\title{
COMPUTER-AIDED PHASE IDENTIFICATION AND FRAME-TO-FRAME ANALYSIS OF ENDODONTIC ASYMMETRIC RECIPROCATION ROTATION: A PRELIMINARY STUDY
}

\author{
ALEŠ FIDLER $^{1}$, EKIM ONUR ORHAN ${ }^{\bowtie, 2}$, ÖZGÜR IRMAK $^{3}$ \\ ${ }^{1}$ Department of Endodontics and Operative Dentistry, Faculty of Medicine, University of Ljubljana, Slovenia, \\ ${ }^{2}$ Department of Endodontics, Faculty of Dentistry, Eskisehir Osmangazi University, Eskişehir, Turkey, \\ ${ }^{3}$ Department of Restorative Dentistry, Faculty of Dentistry, Near East University, Nicosia / TRNC Mersin 10, \\ Turkey \\ e-mail: ales.fidler@mf.uni-lj.si, ekimonurorhan@gmail.com,zgrrmk@gmail.com \\ (Received January 28, 2020; revised April 25, 2020; accepted April 28, 2020)
}

\begin{abstract}
To perform a detailed evaluation of reciprocating motion using a computer-aided phase identification and frame-to-frame analysis, a continuous rotation at $300 \mathrm{rpm}$, RECIPROC ALL mode and WAVEONE ALL-mode were recorded with a high-speed camera. Movie files were automatically analyzed with digital video analysis and modeling tool. RECIPROC ALL mode parameters were $186.34^{\circ} \pm 1.02$ at $428.32 \mathrm{rpm} \pm 7.61$ and $65.07^{\circ} \pm 0.93$ at $261.06 \mathrm{rpm} \pm 7.72$; WAVEONE ALL-mode parameters were $191.39^{\circ} \pm 1.32$ at $523.83 \mathrm{rpm} \pm 14.36$ and $70.13^{\circ} \pm 1.26$ at $316.06 \mathrm{rpm} \pm 8.75$. The variability of rotational speed during the cycle and distinct acceleration -deceleration patterns, was similar for both reciprocating modes. The computer-aided frame-to-frame analysis revealed that asymmetrical reciprocating motion has more complex kinematics demonstrating high peak rotational speed values and different patterns of acceleration and deceleration. While there was a difference in reciprocating cycle duration and rotational speed, both cycles demonstrated a similar dynamic of rotational speed during the cycle.
\end{abstract}

Keywords: frame-to-frame analysis, high speed video analysis, image analysis, kinematics, phase identification.

\section{INTRODUCTION}

Reciprocating motion increases the cyclic fatigue resistance of endodontic instruments, compared to continuous rotation, independent of the endodontic instrument- or root canal anatomy-related variables (Ferreira et al., 2017). The asymmetrical reciprocating motion has been recommended in root canal instrumentation with single-file instrumentation systems (Capar and Arslan, 2016). It was based on the balanced force technique (Roane et al., 1985); as an alternative to continuous rotation tested with a non-specific clockwisecutting rotary file (Yared, 2008).

The Reciproc (VDW GmbH, Munich, Germany) and WaveOne (Dentsply Sirona, Ballaigues, Switzerland) systems are the first representatives with their counterclockwise cutting single file using asymmetrical reciprocating motion generated by their specific endodontic motors. Specific preset reciprocating modes for both systems have been built into these motors, and these preset modes could not be modified in either system. Moreover, the kinematic values for both systems are not entirely disclosed by their manufacturers. There is limited information about the asymmetrical reciprocating motion generated by the reciprocating motors. It has been stated that the Reciproc system generates asymmetrical $150^{\circ}$ counterclockwise $(\mathrm{CCW})$ and $30^{\circ}$ clockwise $(\mathrm{CW})$ rotations at $300 \mathrm{rpm}$ (Kim et al., 2012), and the WaveOne system generates asymmetrical $170^{\circ} \mathrm{CCW}$ and $50^{\circ} \mathrm{CW}$ rotations at $350 \mathrm{rpm}$ (Grande et al., 2015).

The first study, using high-speed video analysis (Fidler, 2014), revealed that angles and angular speed values are significantly different from the assumed values $^{5,6}$ and these observations were further confirmed with subsequent studies (Irmak and Orhan 2018; Orhan et al., 2019). It was also found that the reciprocating motion is more complicated compared to the continuous rotation with the constant angular speed. The reciprocation motion includes not only rotation phases but also standstill phases, needed to stop the motor and change the direction of rotation (Fidler, 2014). The visual analysis of a reciprocating cycle, used in previous studies (Fidler, 2014; Irmak and Orhan 2018; Orhan et al., 2019). is timeconsuming and might be prone to human observer error. 
Most importantly, it assumes the constant angular speed during the rotational phase and therefore, does not provide detailed kinematic analysis. Analysis of the reciprocating cycle using computer-aided methods may reduce the workload, decrease observer related bias, and provide more detailed analysis.

This study aimed to use a computer-aided phase identification and frame-to-frame analysis for detailed evaluation of reciprocating motion of an endodontic motor.

\section{MATERIAL AND METHODS}

A new torque-controlled endodontic motor (VDW Silver Reciproc v1.0. SN: SR3743, VDW GmbH.) with its 6:1 contra-angle hand-piece was evaluated. Motor calibration was performed before the video captures, as recommended by the manufacturer.

A custom disc with $40 \mathrm{~mm}$ diameter with a shaft designed to fit into the contra-angle was manufactured by a computer-numeric-control machine from aluminum (Irmak and Orhan 2018; Orhan et al., 2019). The surface of the disc was painted with matte white paint, and a single black colored dot with a diameter of $1 \mathrm{~mm}$ was marked on the surface, near the edge of the disc (Fig. 1). The black dot was used as the main reference for the image analysis. The target object (disc) was inserted into the Silver Reciproc contraangle which was attached to a clamp placed in front of a high-speed camera (EX-F1; Casio, Tokyo, Japan). All parts and surfaces were aligned using a water level.

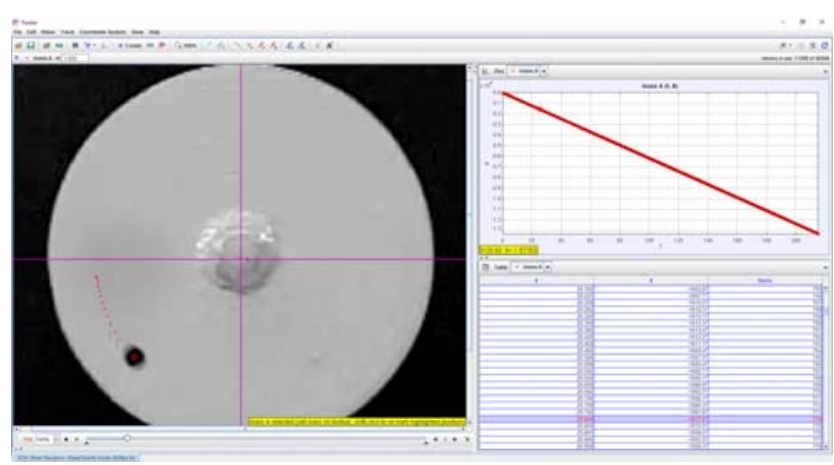

Fig. 1. Screenshot of automated frame-to-frame evaluation. On the left side is a white disc with a black dot, used for automatic tracking. Purple lines represent the coordinate system, positioned in the centre of rotation, small red dots represent sequential positions of the black dot.

The camera was adjusted to high-speed video mode at 600 frames per second (fps) with a resolution of 432 x 192 pixels and recorded in MOV file format
(Video S1 and S2). The disc was illuminated by two light sources (Viltrox L116T LED light, Shenzhen Jueying Technology Co., Ltd., Shenzhen, China). The light outputs of each source were set at $5600 \mathrm{~K}$, 810lux brightness. A continuous rotation and both reciprocating motions, RECIPROC ALL-mode (Rmode) and WAVEONE ALL-mode (W-mode), were captured continuously for $12 \mathrm{~s}$.

\section{EVALUATION OF THE KINEMATICS}

Each recorded movie file was automatically analyzed with Tracker Video Analysis and Modelling Tool v4.11.0. (https://physlets.org/tracker/) installed on a personal computer (Intel i7, 16Gb RAM, 512 GB $\mathrm{SSD}+1 \mathrm{~TB} \mathrm{HD})$. The center of the polar coordinate system, used for angle measurements, was positioned in the axis of rotation, corresponding to the center of the disc. The black dot was identified in the software, and automated dot tracking was applied. The angle of rotation between the two consecutive frames was based on the difference the dot angulation in the polar coordinate system (Fig. 1). For each video, $10 \mathrm{~s}$ segments were analyzed, and two approaches were utilized for evaluation of kinematic data.

\section{AUTOMATED PHASE IDENTIFICATION ANALYSIS}

An automated-phase identification is based on visual identification of the kinematic phases (Fidler, 2014). For continuous rotation, the duration of one rotation $\left(360^{\circ}\right)$ was recorded, and angular rotational speed was calculated. For reciprocating motion, the 4 phases of each cycle, namely engaging rotation, standstill after engaging rotation, disengaging rotation, standstill after disengaging rotation were identified by determination of their corresponding endpoints, determined by the local minima and maximal angle values (Fidler, 2014). Angle and duration of each phase were recorded and used for calculation kinematic parameters, defined in the previous studies (Fidler, 2014; Irmak and Orhan 2018; Orhan et al., 2019), as follows:

- Engaging angle $=\left(^{\circ}\right)\left(\propto_{\mathrm{e}}\right)$

- Disengaging angle $=\left(^{\circ}\right)\left(\propto_{\mathrm{d}}\right)$

- Engaging rotation time $=\mathrm{t}_{\mathrm{er}}$

- Disengaging rotation time $=t_{d r}$

- Reciprocating motion cycle duration $=t_{e r}+t_{e s}+t_{d r}$ $+t_{\mathrm{ds}}$

- Engaging rotational speed $=\left(\propto_{\mathrm{e}} / \mathrm{t}_{\mathrm{er}}\right) \times(60 \mathrm{~s} /$ $\left.360^{\circ}\right)$

- Disengaging rotational speed $(\mathrm{rpm})=\left(\propto_{\mathrm{d}} / \mathrm{t}_{\mathrm{dr}}\right) \mathrm{x}$ $\left(60 \mathrm{~s} / 360^{\circ}\right)$

- Net cycle angle $=\left(^{\circ}\right)\left(\propto_{e}-\propto_{d}\right)$ 


\section{AUTOMATED FRAME-TO-FRAME KINEMATIC ANALYSIS}

This method is based on the calculation of frameto-frame rotational speed from the angle of rotation and time interval between the two consecutive frames. The time delay between two frames was $1 / 600 \mathrm{~s}$, as calculated from 600 FPS video recording. Data of ten rotations and ten reciprocating cycles were acquired frame-to-frame kinematic analysis.

\section{STATISTICAL ANALYSIS}

Descriptive statistical analysis was performed using MS Office Professional 2016 (Microsoft, Redmond, USA).

\section{RESULTS}

The rotational speed of continuous rotation for phase identification and frame-to-frame method were 297.23 and $297.22 \mathrm{rpm}$, respectively and were similar to the set value of 300rpm. The standard deviation of the rotational speed for the frame-to-frame method was $13.58 \mathrm{rpm}$, and it was higher compared to $1.53 \mathrm{rpm}$, obtained with phase identification method.

The reciprocating kinematic values, obtained by phase identification analysis, are given in Table 1. The net cycle angle of both reciprocating modes was approximately $121^{\circ}$, exceeding the assumed value only by $1^{\circ}$. The actual engagement angles of R-mode and $\mathrm{W}$-mode exceeded the assumed values approximately by $35^{\circ}$ and $20^{\circ}$, respectively. Consequently, the difference between engagement angles of the R-mode and the $\mathrm{W}$-mode was only $5^{\circ}$, compared to the assumed value as $20^{\circ}$. The same relationship was found for disengagement angles. The average engaging rotational speed of both reciprocating motion modes was roughly $45 \%$ higher than the assumed values, i.e., 428 versus 300 and 523 versus $350 \mathrm{rpm}$, for the R-mode and the $\mathrm{W}$-mode, respectively (see Table 1). On the contrary, the actual disengaging rotational speeds were approximately $10 \%$ lower than the assumed values. The duration of standstill phases after engaging, and disengaging rotations were longer for the R-mode compared to the $\mathrm{W}$-mode.
The rotational speed, obtained with frame-to-frame analysis, demonstrates the variability of rotational speed during the cycle for both reciprocating modes (Fig. 2). The frame-to-frame rotational speed time plots of 10 averaged the R-mode, and the W-mode cycles were created (Fig. 3).

Table 1. Kinematic values of RECIPROCALL-mode and WAVEONEALL-mode, obtained with automated phase identification analysis.

\begin{tabular}{|c|c|c|}
\hline Parameter & $\begin{array}{l}\text { RECIPRO- } \\
\text { CALL-mode }\end{array}$ & $\begin{array}{l}\text { WAVEONE- } \\
\text { ALL-mode }\end{array}$ \\
\hline Sample size (n) & 87 & 102 \\
\hline Engaging angle $\mathrm{CCW}\left({ }^{\circ}\right)$ & $186.34 \pm 1.02$ & $191.39 \pm 1.32$ \\
\hline $\begin{array}{l}\text { Assumed engaging angle } \\
\mathrm{CCW}\left({ }^{\circ}\right)\end{array}$ & $150.00 \pm 0.00$ & $170 \pm 0.00$ \\
\hline $\begin{array}{l}\text { Disengaging angle } \mathrm{CW} \\
\left({ }^{\circ}\right)\end{array}$ & $65.07 \pm 0.93$ & $70.13 \pm 1.26$ \\
\hline $\begin{array}{l}\text { Assumed disengaging } \\
\text { angle } \mathrm{CW}\left({ }^{\circ}\right)\end{array}$ & $30 \pm 0.00$ & $50 \pm 0.00$ \\
\hline Net cycle angle $\left(^{\circ}\right)$ & $121.27 \pm 0.89$ & $121.26 \pm 1.19$ \\
\hline Engaging speed (rpm) & $428.32 \pm 7.61$ & $523.83 \pm 14.36$ \\
\hline $\begin{array}{l}\text { Assumed engaging speed } \\
(\mathrm{rpm})\end{array}$ & $300 \pm 0.00$ & $350 \pm 0.00$ \\
\hline Disengaging speed (rpm) & $261.06 \pm 7.72$ & $316.06 \pm 8.75$ \\
\hline $\begin{array}{l}\text { Assumed disengaging } \\
\text { speed (rpm) }\end{array}$ & $300 \pm 0.00$ & $350 \pm 0.00$ \\
\hline Engaging time (ms) & $72.53 \pm 1.29$ & $60.93 \pm 1.42$ \\
\hline Disengaging time $(\mathrm{ms})$ & $41.57 \pm 1.17$ & $37.01 \pm 1.23$ \\
\hline Cycle duration (ms) & $114.10 \pm 1.10$ & $97.94 \pm 1.18$ \\
\hline $\begin{array}{l}\text { Standstill after engaging } \\
(\mathrm{ms})\end{array}$ & $5.10 \pm 0.39$ & $4.95 \pm 0.79$ \\
\hline $\begin{array}{l}\text { Standstill after } \\
\text { disengaging }(\mathrm{ms})\end{array}$ & $0.34 \pm 0.68$ & $0.36 \pm 0.69$ \\
\hline $\begin{array}{l}\text { Standstill after engaging } \\
\text { (intervals } 1 / 600 \mathrm{~s} \text { ) }\end{array}$ & $3-4$ & $2-4$ \\
\hline $\begin{array}{l}\text { Standstill after disengaging } \\
\text { (intervals } 1 / 600 \text { s) }\end{array}$ & $0-1$ & $0-1$ \\
\hline
\end{tabular}

(CCW, counter clockwise; CW, clockwise) 
A

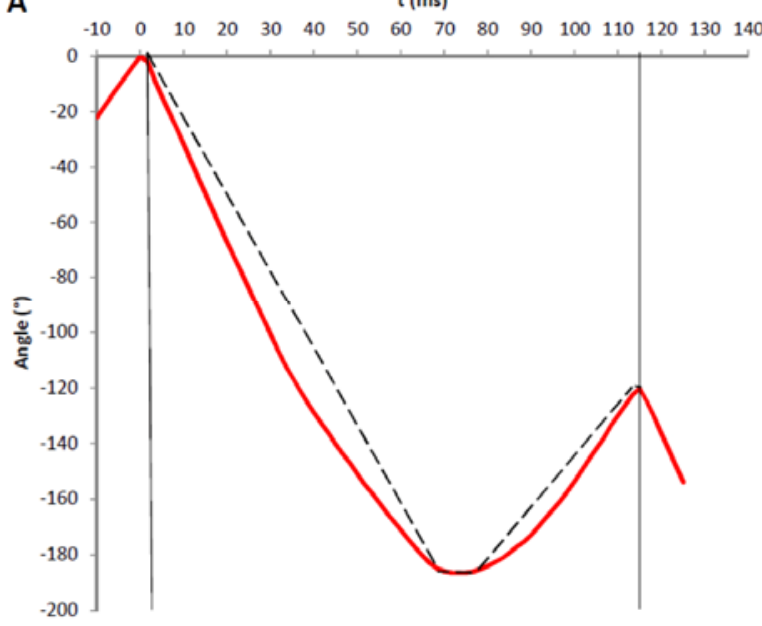

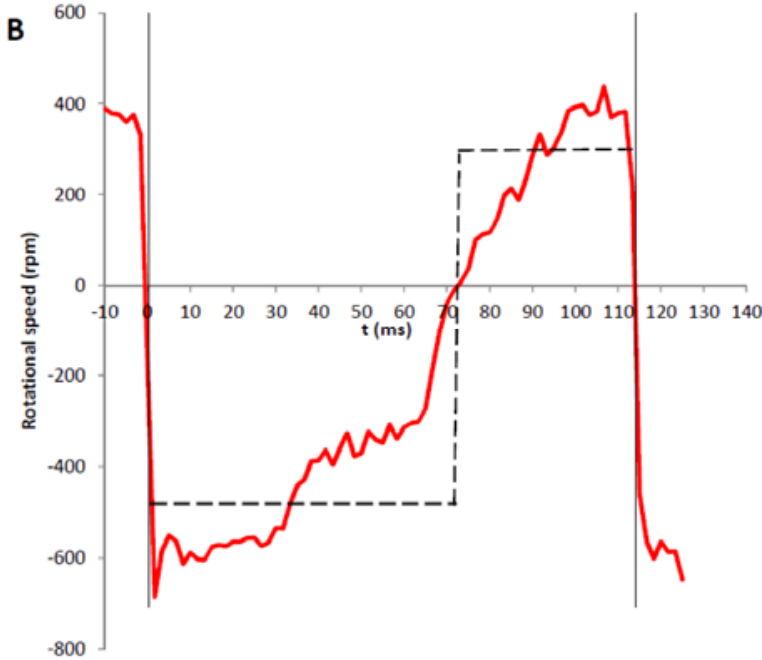

Fig. 2. Analysis of the R-mode reciprocating cycle kinematic. Angle vs time plot (A) and rotational speed vs time plot (B). Beginning and end of the cycle are marked with vertical black lines. The deviation between dashed black lines (automated phase identification method), and red lines (automated frame-to-frame method) indicated the difference between results of phase identification and obtained from the frame-to-frame analysis.

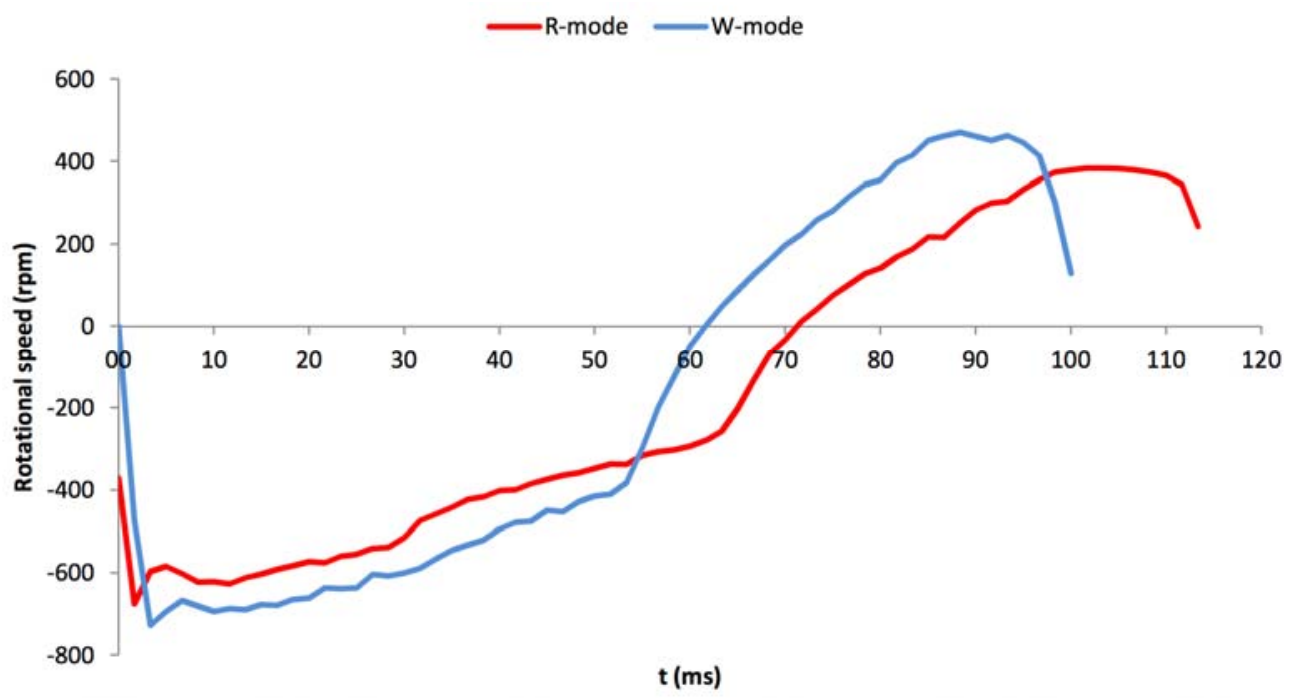

Fig. 3. Rotational speed vs time plot of 10 averaged R-mode (red line) and W-mode (blue line) cycles obtained with automated frame-to-frame analysis. While there is a difference in cycle duration and rotational speed, both cycles demonstrate a similar dynamic of rotational speed during the cycle.

\section{DISCUSSION}

The novel method with frame-to-frame kinematic analysis, applied in the present study, reveals complex rotational speed dynamics during the reciprocating cycle. The momentary rotational speed values were found to exceed the average rotational speed by $50 \%$ and the assumed rotational speed by over $100 \%$. Moreover, the acceleration-deceleration pattern was found to be inverse in engagement and disengagement phase.
The analysis of continuous rotation revealed a minimal difference between the assumed and measured value. The average rotational speed obtained by the automated phase identification method, based on the full rotation cycle, exhibited very low variability, as indicated by SD values of $1.53 \mathrm{rpm}$. In the present study, the standard deviations of rotational speed parameter were higher compared to previous kinematic studies, utilizing visual evaluation (Fidler, 2014; Orhan \& Irmak, 2018; Orhan et al., 2019). The previous study has reported the arbitrary reciprocating motion and the non-normal distribution of kinematic parameters among each RM, however, the authors have evaluated 
the limited dataset obtained visual peak-to-peak analysis (Irmak \& Orhan, 2018). Contrarily, the computer-aided frame to frame analysis method evaluated a huge number of a dataset (7200 frames data per each mode) and revealed a SD of 13.58, indicating a small instability of rotational speed, i.e., jitter, of about $4 \%$. In literature, computer-assisted measurements have been utilized in numerous researches related medical and paramedical field due to their advantages (Dembia et al., 2012; Robert-Inacio et al., 2012; Alilou \& Kovalev, 2013; Alilou et al., 2014; Mapayi et al., 2016; Mabaso et al., 2018; Skwirczyński et al., 2019). These studies have been pointed out that the manual assessment of angle, speed, image analysis measurement has been time-consuming and the inevitable errors may have been seen.

Currently, there has no external calibration device existed for RM endo motors. However, internal calibration specifications were installed into their RM devices such as SILVER.RECIPROC, GOLD.RECIPROC, X-Smart Plus etc. All of these manufacturers recommend making calibration before operations. However, when the activate calibration mode of RM motor, these devices only rotate in the $\mathrm{CW}$ direction. Therefore, only the continuous rotation at $600 \mathrm{fps}$ was used to calibrate for analysis. It could be concluded that the motor was capable of maintaining constant rotational speed, closely matching the assumed value.

The automated phase identification method revealed the high similarity between engagement and disengagement angles, as the actual difference was $5^{\circ}$ compared to an assumed difference of $20^{\circ}\left(150^{\circ}\right.$ versus $170^{\circ}$ for engagement and $30^{\circ}$ versus $50^{\circ}$ for disengagement). The net cycle angle was similar to as declared, i.e., $121.3^{\circ}$ versus $120^{\circ}$ for both reciprocating modes. This is in accordance with a previous evaluation of the same model of an endodontic motor regarding the angle similarity of both reciprocating modes and net cycle angle (Fidler, 2014). Fidler (2014) has noted that the kinematics of reciprocating motion was more complex than it seems as described $\left(150^{\circ}\right.$ $\mathrm{CCW}, 30^{\circ} \mathrm{CW}$ at $300 \mathrm{rpm}$ for RECIPROC ALL mode and $170^{\circ} \mathrm{CCW}, 50^{\circ} \mathrm{CW}$ at $350 \mathrm{rpm}$ for WAVEONE ALL mode). The argument has been discussed with the results of $158.69^{\circ} \mathrm{CCW}$ at $329.05 \mathrm{rpm} \& 34.65^{\circ} \mathrm{CW}$ at $250.16 \mathrm{rpm}$ for the RECIPROC ALL mode and of $159.85^{\circ} \mathrm{CCW}$ at $498.69 \mathrm{rpm} \& 41.44^{\circ} \mathrm{CW}$ at 294.31 rpm for the WAVEONE ALL mode. These have been the first original findings about reciprocating motion kinematics in an endodontic motor (VDW.SILVER®RECIPROC®) (Fidler, 2014). The phase identification method was presented that $186.34^{\circ} \mathrm{CCW} \& 65.07^{\circ} \mathrm{CW}$ for the RECIPROC ALL mode and $191.399^{\circ} \mathrm{CCW} \& 70.13^{\circ} \mathrm{CW}$ for the WAVEONE ALL mode with acceleration to values above $700 \mathrm{rpm}$ in the present study. The new computer-aided phase identification and frame-toframe analysis are obviously more precise and detailed than to the visual peak-to-peak analysis. Therefore, these findings obtained by computer-aided analysis could be more clinically relevant than the previous findings using peak-to-peak visual analysis. The speed of rotation is an independent variable of the fatigue resistance of NiTi instruments. Regardless of the direction, the rotational speed above $700 \mathrm{rpm}$ could negatively affect on the cyclic fatigue life of any instrument (Ferreira et al., 2017). Another study, using a different brand of an endodontic motor (Irmak and Orhan 2018), also reported similarity between the reciprocating modes regarding engagement and disengagement angles, while the net cycle angles were roughly $20^{\circ}$ to $30^{\circ}$ smaller than assumed, with values between $90^{\circ}$ and $100^{\circ}$.

The phase identification method, whether visual or automatic, can only measure the average rotational speed during the engagement and disengagement phases. The lack of ability to measure momentary speed represents a considerable limitation as continued changing the rotation direction, inherent to reciprocating motion, requires persistent acceleration and deceleration. This can only be detected by measuring the momentary speed during the cycle. The proposed automated frame-to-frame analysis facilitates such analysis, and the advantage of this method over the phase identification can be seen in angle vs. time plot (Fig. 2). The plot demonstrates that the rotational speed is not constant throughout each phase, as it is assumed by phase identification method and represented with a straight, inclined line during both rotation phases and straight horizontal line during both standstill phases (Fig. 2). In contrast, the frame-toframe method reveals a non-linear angle vs. time relationship, deviating from the straight line and representing a variable speed during both rotation phases (Fig. 2). Additionally, the transition from disengaging to engaging is sharp, while the transition from engaging to disengaging is smooth.

The angular speed vs time plot (Fig. 2). even further illustrates the difference between both methods. The phase identification method generates horizontal lines, representing the average speed during rotation phases or zero speed during the standstill phases. The transitions between the phases are connected by 
vertical lines (Fig. 2). assuming an immediate change of rotation. This is impossible as it would require infinite acceleration and deceleration. On the contrary, frame-to-frame analysis demonstrates a high variation in rotational speed during the reciprocating cycle. The variable inclination of the curve indicates variable acceleration and deceleration (Fig 2).

A comparison of rotational speed dynamics between R-mode and W-mode was performed on ten averaged cycles (Fig. 3). Despite the difference in cycle duration and average speeds, both cycles demonstrate a similar dynamic of rotational speed during the cycle in terms of acceleration and deceleration. A very fast acceleration was found at the beginning of the engaging phase, leading to a temporary rotational speed over $700 \mathrm{rpm}$, that was achieved in less than 5ms (Fig. 3 ). For both modes, the peak phase rotational speed was approximately $50 \%$ higher than average actual phase rotational speeds and more than $100 \%$ higher than assumed speed. This was followed by slow deceleration leading to a stand-still phase after the engagement phase. The disengagement phase was characterized by opposite acceleration-deceleration pattern, starting with slow acceleration, achieving the maximum rotational speed at the end of the disengagement phase, followed by fast deceleration (Fig. 3). The frame-to-frame analysis also confirmed higher rotational speeds and shorter cycle duration of $\mathrm{W}$-mode in comparison to R-mode, confirming the results of the phase evaluation method.

The first study, evaluating kinematics, proposed visual phase identification method and defined phases and parameters for kinematics description (Fidler, 2014). Two other studies used similar methods and also confirmed the phases (Irmak and Orhan 2018; Orhan et al., 2019). Typically, all of these studies evaluated a limited number of cycles, i.e., ten cycles at 6-second intervals within 1 minute of video (Fidler, 2014) or 20 cycles in 10 continuous seconds (Irmak and Orhan 2018; Orhan et al., 2019). In this study, each mode was recorded for $12 \mathrm{~s}$. One of the reasons for a limited number of evaluates is a time-consuming and fatiguing evaluation. For each cycle, between 70 and 150 images have to be reviewed, aiming to identify five images, depicting phase boundaries. This is followed by angle measurement and recording. The proposed automated video analysis method enables rapid evaluation of a large number of cycles and recording of measurements in a computer file, ready for the calculation of kinematic parameters. An additional advantage of the computer-aided analysis the ability of frame-to-frame analysis. As shown above, it reveals considerable variations in temporal rotational speed variability and acceleration -deceleration patterns. It should be noted that this study analyzed the kinematics of a freely rotating target object. However, the real-time kinematics of reciprocating endodontic motors should also be tested under conditions that simulate clinical usage and canal shaping.

While rotational speed was constant in the continuous rotation, this was not valid for reciprocating motion, as revealed by our results. A study demonstrated that the direction of reciprocation does not affect cyclic fatigue resistance, assuming that the ratio between the engaging and disengaging angles is the same (Gambarini et al., 2012). However, the CW and $\mathrm{CCW}$ angle and angle of progression affect the cyclic fatigue resistance (Gambarini et al., 2012). A study found no difference in cyclic fatigue resistance between "RECIPROC ALL" and "WAVEONE ALL" was found (Pedulla et al., 2013). One of the possible reasons for lack of differences between the reciprocating modes might be the lack of difference in kinematics parameters. It seems reasonable that studies evaluating the effect of instrument motion of their longevity or efficiency would include evaluation of kinematics and thus precluding the "black box" principle. The recent studies have demonstrated that instrument kinematics is the most important factor as well as its metallurgical properties for its cyclic failure life (Ertugrul and Orhan 2019; Orhan and Ertuğrul 2020).

Instrument related factors of its fatigue life such as design, taper, metallurgical properties of NiTi alloy, and manufacturing strategies have well defined (Cheung et al., 2007). In this case, the metallurgical and manufacturing strategies of the instrument production appear to be of ultimate significance (Zinelis et al., 2010; Ferreira et al., 2017). Recently, RECIPROC ${ }^{\circledR}$ Blue (VDW $\mathrm{GmbH}$ ) instrument has introduced as using heat-treated Blue-wire NiTi alloy (Bürklein et al., 2019). Although RECIPROC® Blue has presented better root canal preparation performance than the original RECIPROC@ instruments were made of M-wire NiTi, all VDW motors (VDW.CONNECT Drive ${ }^{\circledR}, \quad$ VDW.GOLD ${ }^{\circledR}$ RECIPROC ${ }^{\circledR}$ and VDW.SILVER ${ }^{\circledR} R E C I P R O C()$ are recommended to use with RECIPROC ${ }^{\circledR}$ Blue instruments at the same specific motor settings (RECIPROC or RECIPROC ALL modes) for safe operation (RECIPROC ${ }^{\circledR}$ Blue official). Furthermore, the novel WaveOne Gold instruments with Gold-wire NiTi (Dentsply Sirona) has used the same kinematics with original WaveOne instruments with M-wire $\mathrm{NiTi}$ in its specific 
Endodontic motor (PROMARK ${ }^{\circledR}$, DENTSPLY Sirona Inc., Tulsa Dental, TN USA) (ProMark ${ }^{\circledR}$ Official).

Regardless of RM modes (W-mode or R-mode), there have been reported that some kinematic parameters have influenced by the clinical usage of "the same brand RM motors" in a recent study (Irmak \& Orhan, 2018). Moreover, both previous studies have used the same visual peak-to-peak analysis method, for the same RM modes, SILVER.RECIPROC(Fidler, 2014) and X-SMART Plus (Irmak \& Orhan, 2018) have shown different kinematics. Likewise, there might be also a variation between each RM handpiece and RM motor offering different serial numbers that may have different speeds, angles, and different other parameters. All motors used in continuous rotation also offer a kind of reciprocation motion: They have an "auto-reverse" function to create more safety during root canal preparation. Hence, they all offer $\mathrm{CW}$ and CCW motions - meaning more or less a reciprocating motion. Bürklein et al. (2019b) demonstrated huge differences of dynamic torque values in the cutting direction compared to the releasing direction of endodontic instruments. The dynamic torque peaks during preparation are directly related to the changes in the rotating directions (Bürklein et al., 2019b). Realtime dynamic torque values and axial forces during the preparation of straight root canals using three different endodontic motors and hand preparation (Bürklein et al., 2019b). Hence, this study corroborates the present findings.

Casio EX-F1 test device is capable to capture up to 1200 FPS. Formerly, a pilot test had made at 600 FPS with 432 x 192 pixels and 1200 FPS with 336 x 96 pixels, respectively. Although higher FPS would increase the time resolution, the angle resolution would be decreased due to lower image resolution. The 600 FPS with $432 \times 192$ pixels video recording was found to be the optimal mode for both time and angle resolution. Further studies can be made with sophisticated high-resolution video recorders at $1000+$ FPS on different motors/devices.

The outcomes of the study may not aid directly clinical impacts. The real output details of notadjustable set kinematics are crucial data for manufacturers and researchers of this field for their research \& development studies. The independent research data that obtained with a high-precision analyzing methodology must be available in the literature. The data could be collected from randomly selected one of the quality-controlled medical products. In literature, the analyses of the kinematic parameters of reciprocating motions were evaluated using only single motor per experimental group. There have not been any exceptions in the literature regarding the motor quantity (Fidler, 2014; Irmak and Orhan 2018; Orhan et al., 2019, Pirani et al., 2017; Iacono et al., 2019).

Fidler (2014) analyzed single Silver Reciproc v1.0 (VDW, GmbH), very recently Iacono et al. (2019) analyzed and compared the kinematics of single $\mathrm{X}$ Smart Plus (Dentsply Sirona, Balleagues, Switzerland) with single sample unit of a new generation reciprocating motor (EVO, Cefla, Imola, Italy) and the preliminary results of the study had been presented by Pirani et al. (2017). Irmak \& Orhan (Irmak and Orhan 2018) used single X-Smart Plus motor (Dentsply Sirona) per group. Orhan et al. (Orhan et al., 2019) analyzed single reciprocating contra-angle hand-piece (Reciproc Direct, VDW $\mathrm{GmbH}$ ). Additional comparisons with other reciprocating motors could be considered in future study designs.

\section{CONCLUSION}

The asymmetrical reciprocating movement was evaluated using phase identification and frame-toframe method. The frame-to-frame analysis revealed that asymmetrical reciprocating motion has more complex kinematics demonstrating high peak rotational speed values and different patterns of acceleration and deceleration. While there was a difference in reciprocating cycle duration and rotational speed, both cycles demonstrated a similar dynamic of rotational speed during the cycle.

\section{SUPPORTING INFORMATION}

Additional supporting information may be found in the online version of this article:

Supplementary 1. Silver Reciproc ${ }^{\circledR}$ v1.0 (VDW $\mathrm{GmbH}$ ) at RECIPROC ALL mode.

Supplementary 2. Silver Reciproc ${ }^{\circledR}$ v1.0 (VDW $\mathrm{GmbH}$ ) at WAVEONE ALL mode.

\section{ACKNOWLEDGEMENTS}

All authors have contributed significantly to this research project and are in agreement with this manuscript. We do not have any conflict of interest to declare. 


\section{REFERENCES}

Alilou M, Kovalev V (2013). Automated object detection and segmentation of the histocytology images using reshapable agents. Image Anal Stereol 32: 89-99.

Alilou M, Kovalev V, Snezhko E, Taimouri V (2014). A comprehensive framework for automatic detection of pulmonary nodules in lung CT images. Image Anal Stereol 33: 13-27.

Bürklein S, Flüch S, Schäfer E (2019a). Shaping ability of reciprocating single-file systems in severely curved canals: WaveOne and Reciproc versus WaveOne Gold and Reciproc blue. Odontology 107, 96-102.

Bürklein S, Stüber JP, Schäfer E (2019b). Real-time dynamic torque values and axial forces during preparation of straight root canals using three different endodontic motors and hand preparation. International endodontic journal 52: 94-104.

Capar ID, Arslan H (2016). A review of instrumentation kinematics of engine-driven nickel-titanium instruments. Int Endod J 49:119-35.

Cheung GS, Shen Y, Darvell BW (2007). Effect of environment on low-cycle fatigue of a nickel-titanium instrument. J Endod 33, 1433-7.

Dembia C, Liu Y, Avedisian C (2012). Automated data analysis for consecutive images from droplet combustion experiments. Image Anal Stereol, 31: 137-48.

Ertuğrul IF, Orhan EO (2019). Cyclic fatigue and energydispersive X-ray spectroscopy examination of the novel ROTATE instrument. Microscopy Res \& Tech 82:2042-8.

Ferreira F, Adeodato C, Barbosa I, Aboud L, Scelza P, Zaccaro Scelza M (2017). Movement kinematics and cyclic fatigue of NiTi rotary instruments: a systematic review. Int Endod J 50:143-52.

Fidler A (2014). Kinematics of 2 reciprocating endodontic motors: the difference between actual and set values. J Endod 40:990-4.

Gambarini G, Rubini AG, Al Sudani D, Gergi R, Culla A, De Angelis F, Di Carlo S, Pompa G, Osta N, Testarelli L (2012). Influence of different angles of reciprocation on the cyclic fatigue of nickel-titanium endodontic instruments. J Endod 38:1408-11.

Grande NM, Ahmed HM, Cohen S, Bukiet F, Plotino G (2015). Current assessment of reciprocation in endodontic preparation: a comprehensive review-part I: Historic perspectives and current applications. J Endod 41:1778-83.

Iacono F, Pirani C, Arias A, de la Macorra JC, Generali L, Gandolfi MG, Prati C (2019). Impact of a modified motion on the fatigue life of NiTi reciprocating instruments: a Weibull analysis. Clin Oral Invest 23:3095-102.
Irmak O, Orhan EO (2018). Kinematic analysis of new and used reciprocating endodontic motors in 2 different modes. Int J Artif Organs 41:17-22.

Kim HC, Kwak SW, Cheung GS, Ko DH, Chung SM, Lee W (2012). Cyclic fatigue and torsional resistance of two new nickel-titanium instruments used in reciprocation motion: Reciproc versus WaveOne. J Endod 38:541-

Mabaso M, Withey D, Twala B (2018). Spot detection methods in fluorescence microscopy imaging: a review. Image Anal Stereol 37: 173-90.

Mapayi T, Tapamo J, Viriri S, Adio A (2016). Automatic retinal vessel detection and tortuosity measurement. Image Anal Stereol 35: 117-35.

Orhan EO, Irmak O, Ertuğrul IF (2019). Kinematics of a novel reciprocating endodontic handpiece. Int Endod J 52: 1235-43.

Orhan EO, Ertuğrul IF (2020). Cyclic fatigue life of novel rotary compactors: A scanning electron microscopy evaluation. Microscopy Res \& Tech 83: 66-71.

Pedulla E, Grande NM, Plotino G, Gambarini G, Rapisarda E (2013). Influence of continuous or reciprocating motion on cyclic fatigue resistance of 4 different nickel-titanium rotary instruments. J Endod 39:258-61.

Pirani C, Iacono F, Generali L, Gatto MR, Gandolfi MG, Prati C (2017). Impact of a modified kinematic on the fatigue life of reciprocating instruments. At: www.es-e.eu/ese-biennial- congress/brussels2017/absinfo/ESE-Brussels-2017-OralPresentations.pdf. Accessed on July 42019.

PROMARK Endodontic Motor Official https://shop.dentsplysirona.com/content/dam/master/p roduct-procedure-brandcategories/endodontics/productcategories/endodontic-equipment/motors-and-contraangles/motors/promark/documents/END-DFUProMark-Motor-EN.pdf Access date 13 April 2020.

RECIPROC Blue official https://www.vdwdental.com/fileadmin/Dokumente/Sortiment/Aufbereitun g/Reziproke-Aufbereitung/RECIPROC-blue/VDWDental-RECIPROCblue-User-Brochure-EN.pdf Access date 13 April 2020.

Roane JB, Sabala CL, Duncanson MG Jr (1985). The 'balanced force' concept for instrumentation of curved canals. J Endod 11:203-11.

Robert-Inacio F, Oudinet G, Colonna F (2012). Ship classification from multispectral videos. Image Anal Stereol 31: 121-35.

Skwirczyński M, Gąciarz T, Skomorowski M, Wojciechowski W (2019). Automated measurement 
of foot deformities: flatfoot, high arch, calcaneal fracture. Image Anal Stereol 38: 161-72.

Yared G (2008). Canal preparation using only one Ni-Ti rotary instrument: preliminary observations. Int Endod J 41:339-44.
Zinelis S, Eliades T, Eliades G (2010). A metallurgical characterization of ten endodontic Ni-Ti instruments: assessing the clinical relevance of shape memory and superelastic properties of $\mathrm{Ni}-\mathrm{Ti}$ endodontic instruments. Int Endod J 43, 125-34. 